\title{
Design and Implementation of Real-Time Health Vital Sign Monitoring Device with Wireless Sensor-based on Arduino Mega
}

\author{
Bekti Wulandari, Satriyo Agung Dewanto, Mentari Putri Jati, Muhammad Munir, Andhika \\ Angga Setiyawan \\ ${ }^{1}$ Engineering Faculty, Universitas Negeri Yogyakarta, D.I. Yogyakarta, Indonesia \\ *E-mail: bektiwulandari@uny.ac.id
}

\begin{abstract}
This paper discusses the realization of vital sign monitoring devices and knowing their performance. This device is expected to assist medical personnel in measuring and monitoring vital signs without having to have physical contact with patients. The design phase of the patient's vital sign monitoring device with an Arduino Mega-based wireless sensor starts from the identification, needs analysis, design, manufacture, troubleshoot, and testing. Arduino Mega and ESP8266 as the main components that function for the controller and upload data to the server. Then MAX30100, DS18B20, and MPX5700AP sensors which function to detect the vital sign. Android smartphones are used to display measurement results in real-time, save and display vital sign data records. Based on the test results, the patient's vital signs monitoring device has an average difference of $0.67 \%$ for temperature checks, $1.19 \%$ for pulse checks, $0.77 \%$ for SPO2 examinations, $4.78 \%$, and $8.91 \%$ for systolic and diastolic blood pressure examinations.
\end{abstract}

Keywords: vital sign monitoring device, wireless sensor, arduino mega

\section{INTRODUCTION}

Checking vital conditions is very important to know a person's physical condition. Because if health is disturbed it will affect daily activities [1]. Checking vital conditions is also one of the things that must be monitored by medical personnel regularly for hospitalized patients [2], [3]. Checking vital conditions includes checking blood pressure, body temperature, heart rate/pulse, and monitoring blood oxygen levels and respiratory rate [4]. By checking the patient's vital condition, the doctor will get data that can be used to analyze the disease to determine the appropriate dose and type of drug for the patient. In addition, data recording is also important to monitor the progress of the patient's condition, especially patients undergoing hospitalization and patients undergoing independent isolation. Therefore, regular checks of the patient's vital condition must be carried out to monitor the patient's body condition.

However, the world is currently experiencing a COVID-19 pandemic. Covid-19 is a collection of viruses that can infect the respiratory system caused by viruses from Corona virus group, namely SARS-CoV-2. In many cases, this virus can cause severe respiratory infections, such as lung infections (pneumonia). Corona virus is transmitted through phlegm (droplets) from the respiratory tract and also direct contact with patients with COVID-19 [5].

On January 27, 2021, the Indonesian Doctors Association (IDI) mitigation team revealed that 647 Indonesian medical personnel who died from COVID-19 had died. The mortality ratio of medical personnel and health workers in Indonesia is among the highest in the world compared to other countries [6]. The deputy administrator of the Indonesian Doctors Association analyzed that the initial death of doctors was not only due to protective equipment or personal protective equipment (PPE), but was related to standardization of service systems and regulations during the COVID-19 pandemic. Including the problem of the heavy workload of medical personnel in serving Covid-19 patients. 
In general, to check body temperature using a mercury thermometer or digital thermometer, for heart rate and oxygen levels in the blood an oximeter and sphygmomanometer are used to measure blood pressure. The examination requires doctors and patients to make physical contact [7]. This is one of the medical personnel who has contracted COVID19. So it is necessary to make a tool to check or monitor the patient's vital signs without any physical contact between medical personnel and patients, to reduce the risk of spreading the Covid-19 virus between medical personnel and patients.

The use of vital sign monitoring devices wireless sensors is one of the technologies that are developing both using the internet with Zigbee protocol [8], [9], and with Bluetooth [10] which can be monitored remotely on each smartphone - respectively.

Based on the research that has been done, this paper discusses the design of a patient's vital sign monitoring device with an Arduino megabased wireless sensor. This monitoring tool is equipped with DS18B20, MPX5700AP, and MAX30100 sensors to detect vital sign values in patients. For the appearance of monitoring data, it will be stored in the Google Firebase cloud and displayed in real-time on smartphones, so that medical personnel can monitor or check the patient's vital condition without direct contact with the patient and also the work of medical personnel will be lighter and can reduce the risk of medical personnel and patients being exposed to Covid -19 .

\section{METHODS}

The block circuit diagram is a basic description of a series of tools to be made. Each block represents a component or circuit that has a specific function. The following is a block diagram of a patient's vital sign monitoring device with an Arduino mega-based wireless sensor.

The block diagram in Figure 1 illustrates the parts of the patient's vital sign monitoring device with an Arduino mega-based wireless sensor in the form of a body temperature detection circuit using the DS18B20 sensor.

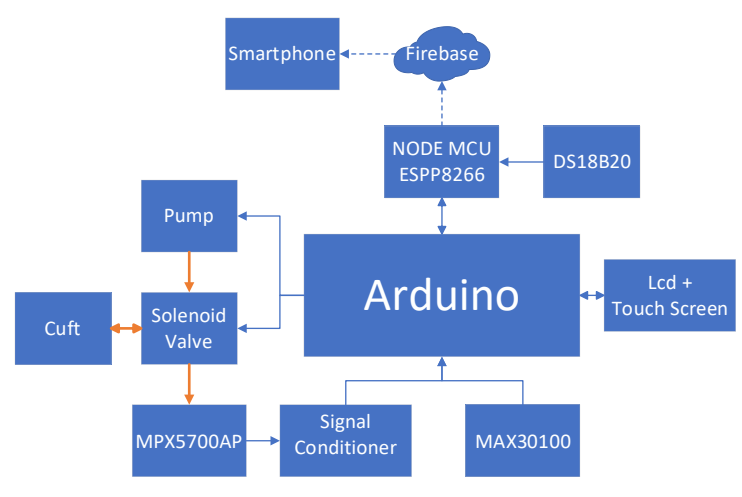

Figure 1. System block diagram.

This sensor is connected to esp8266 so that after the sensor detects the temperature, the measured temperature will be sent to google firebase which can later be displayed on the smartphone application.

The pulse oximeter detection circuit uses the Max30100 sensor to detect pulse and blood oxygen levels (SPO2). Max30100 will detect the difference in the wavelength reflected by the LED and infrared to the finger. Blood that contains oxygen will absorb the wavelength produced by infrared of $900 \mathrm{~nm}$ while blood that does not contain oxygen will absorb the wave produced by the LED which is $650 \mathrm{~nm}$. Then the signal or wavelength difference will be processed by Arduino Mega which will then be sent to Esp8266 to be uploaded to Google Firebase so that it can be accessed or displayed on the smartphone application.

Then the blood pressure detection circuit uses a pump that will pump the cuft to compress the arteries so that the blood pressure will stop. After the blood pressure stops, the solenoid valve will open and release the air pressure in the cuft. As long as the wind pressure is issued, the sensor will detect oscillometer waves or corroding sound waves. Korotkoff is a method for determining the value of blood pressure based on the pulse because blood is pumped by the heart [11]. After the oscillometric wave is detected, the signal from the mpx5700ap sensor will be 
forwarded to the signal conditioning circuit and then processed by the arduino mega. The signal from the oscillometric wave that has been processed by Arduino Mega will be a blood pressure value and then sent to esp8266 to be uploaded to Google Firebase and displayed on the smartphone application.

Next is a series of user interfaces consisting of an ili9488 TFT LCD and touch screen. The LCD is used to inform the running of the tool or display commands to the user as to what to do and what the tool is doing. While the touch screen is used to give commands to the device by pressing the icon on the screen. The LCD and touch screen are processed by Arduino Mega.

The server used is a firebase database which is non-SQL database storage that allows saving several types of data. These data types include string, Long, and Boolean data. Data in firebase is stored as JSON (JavaScript Object Nation) objects, which is a format for storing or exchanging human-readable information. Firebase has two interesting features, namely Remote Config and Firebase Real-Time Database [12].

\section{CIRCUIT DESIGN}

The thing that must be determined in the design of the tool is the electronic circuit scheme and the design of the tool. The equipment circuit scheme is needed to facilitate the process of making tools, especially in the manufacture of PCB boards, besides that the electronic circuit scheme can make it easier to repair tools if the tools experience problems or damage.

Figure 2 is a schematic of the voltage regulator circuit which is required to lower the voltage from the source voltage to the working voltage of each component. This regulator circuit uses the $\operatorname{lm} 2596 \mathrm{~s}$ ic as the main component [13].

In the signal conditioning circuit, there are 3 conditioning processes, namely, a buffer to buffer the signal from the sensor so that the voltage from the sensor is not affected by impedance when it enters the next circuit that shown in Figure 3.
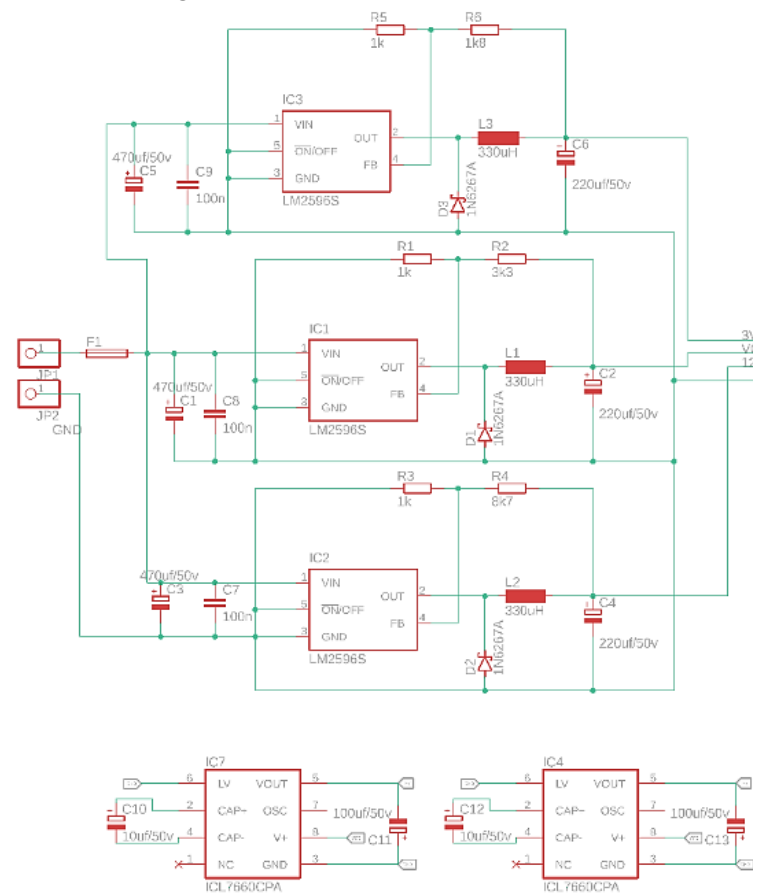

Figure 2. Regulator circuit design.

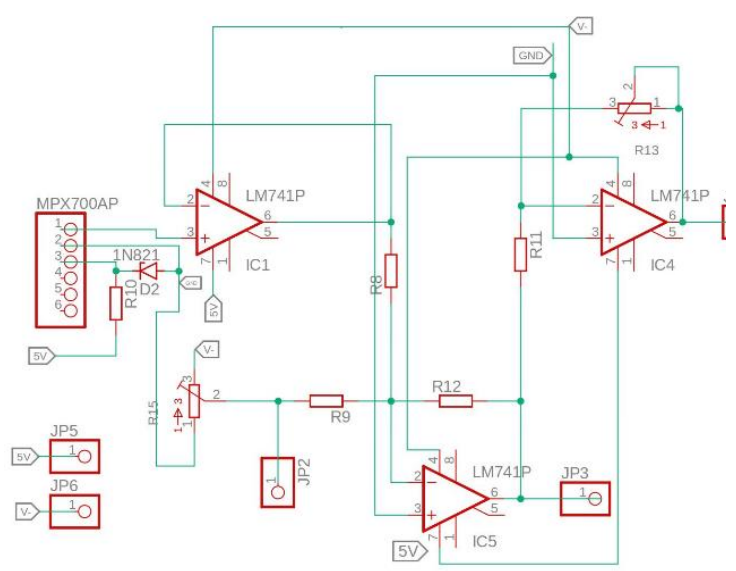

Figure 3. Signal conditioning circuit design.

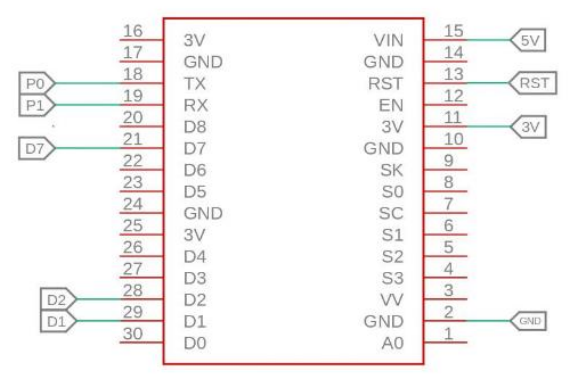

Figure 4. ESP8266 circuit design. 


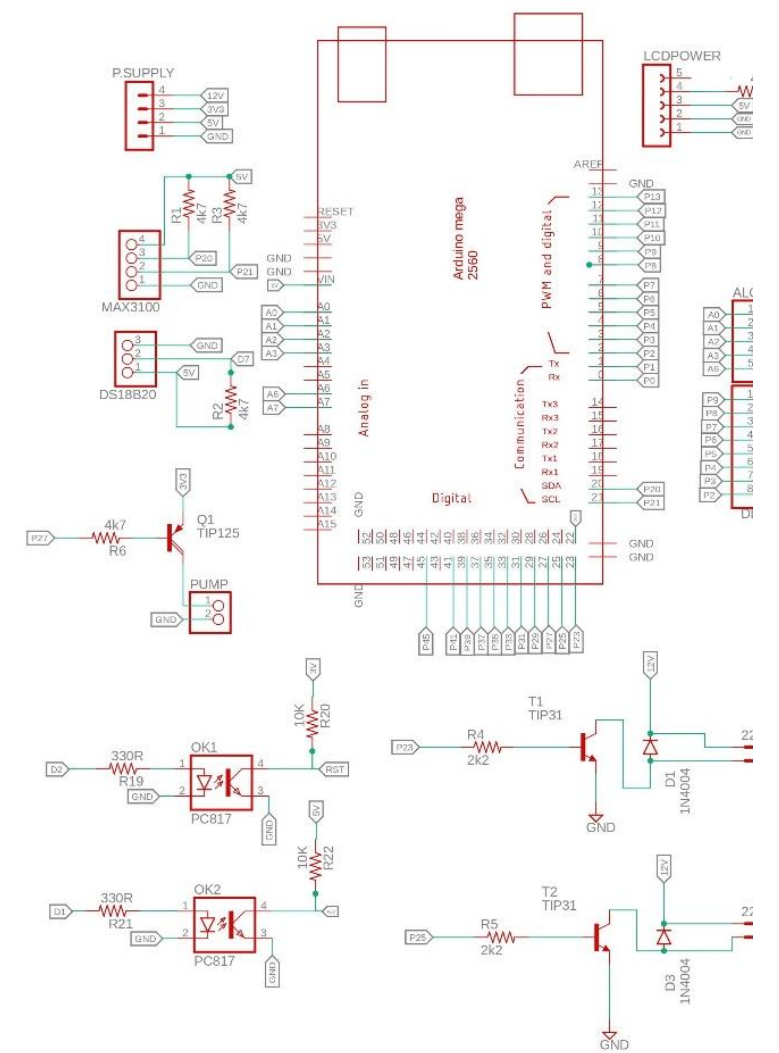

Figure 5. Main PCB Arduino Mega circuit design.

Next is the adder, the adder circuit in signal conditioning serves to reduce or increase the voltage from the sensor so that the voltage from the sensor is zero before the sensor reads air pressure. The last is inverting, because the summing amplifier uses an inverting amplifier, the voltage needs to be changed so that it becomes positive again by adding an inverting circuit with a gain of 1 time.

Figure 5 is a schematic of the device's microcontroller board circuit. The mainboard circuit contains Arduino Mega as a control component, esp8266 as a wifi module, supporting drivers, and a signal conditioning circuit.

After the scheme of the next series of tools is the design of the shape of the tool. The patient's vital sign monitoring device is designed in the form of an instrument box, the body temperature sensor and pulse oximeter are outside the box for easy use to the patient. The instrument box used has a size of $231 \mathrm{~mm} \mathrm{x}$ $210 \mathrm{~mm} \times 80 \mathrm{~mm}$. The casing is used to protect tool components and make it easier for users to place, store and use tools. Here is a drawing of the tool design in Figure 6.

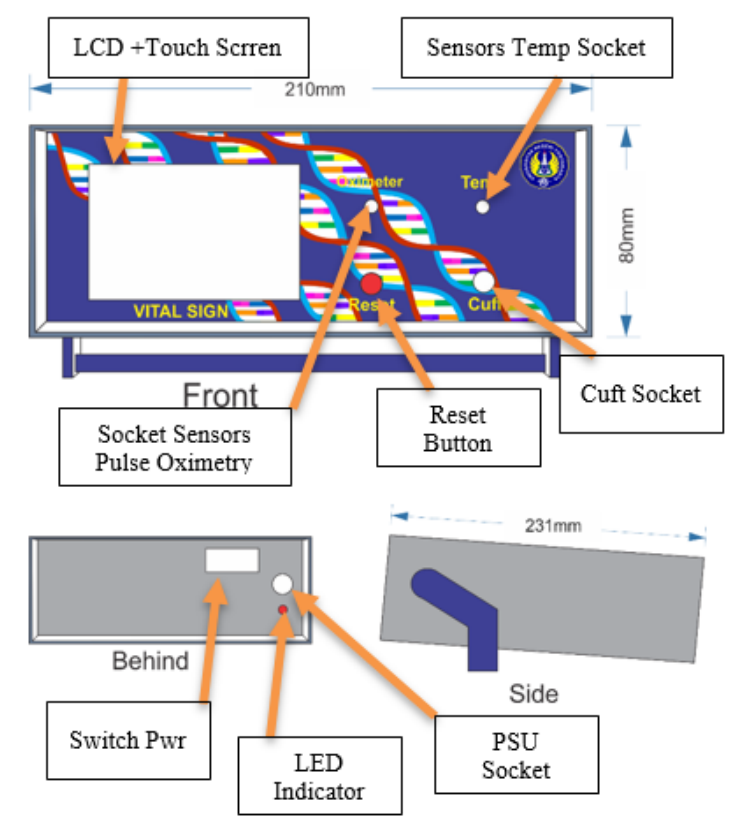

Figure 6. Device design.

\section{SOFTWARE DESIGN}

Arduino mega and esp8266 board programming using Arduino IDE software. This software uses the $\mathrm{C}$ programming language. Making the Arduino program itself begins with initializing which pins will be used by the system. Figure 7 is a flowchart of a patient's vital sign monitoring system with a wireless sensor based on Arduino Mega.

Initialize ports and global variables. Then the LCD will display a command so that the user presses the Run button on the layer to start measuring body temperature, pulse, and oxygen levels in the blood. When the Run button is pressed, a prompt appears to press the Reset button to start the measurement. After pressing the Reset button, the device will enter the temperature check and heart check subroutine to monitor the patient's body temperature, heart rate, and oxygen levels. At that time the LCD will display information if you want to check blood pressure then press the Run button.

If the run button is pressed, it will enter the blood pressure check subroutine and the device 
will take blood pressure measurements. And if the measurement has been completed the LCD will give instructions to press the exit button. In every subroutine or every measurement of the vital sign data obtained, it will always be uploaded to firebase and displayed on the smartphone application.

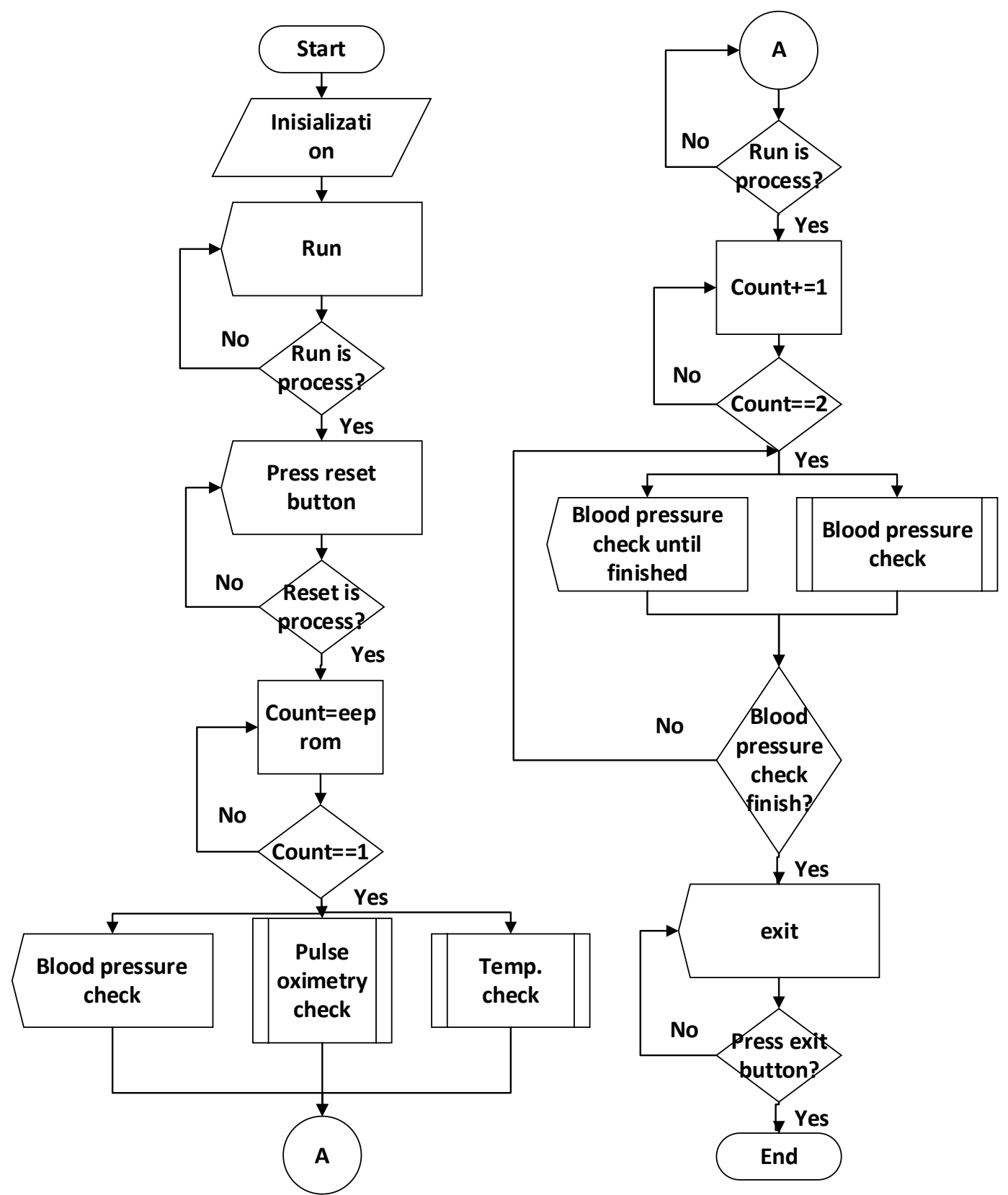

Figure 7. Whole system flowchart. 


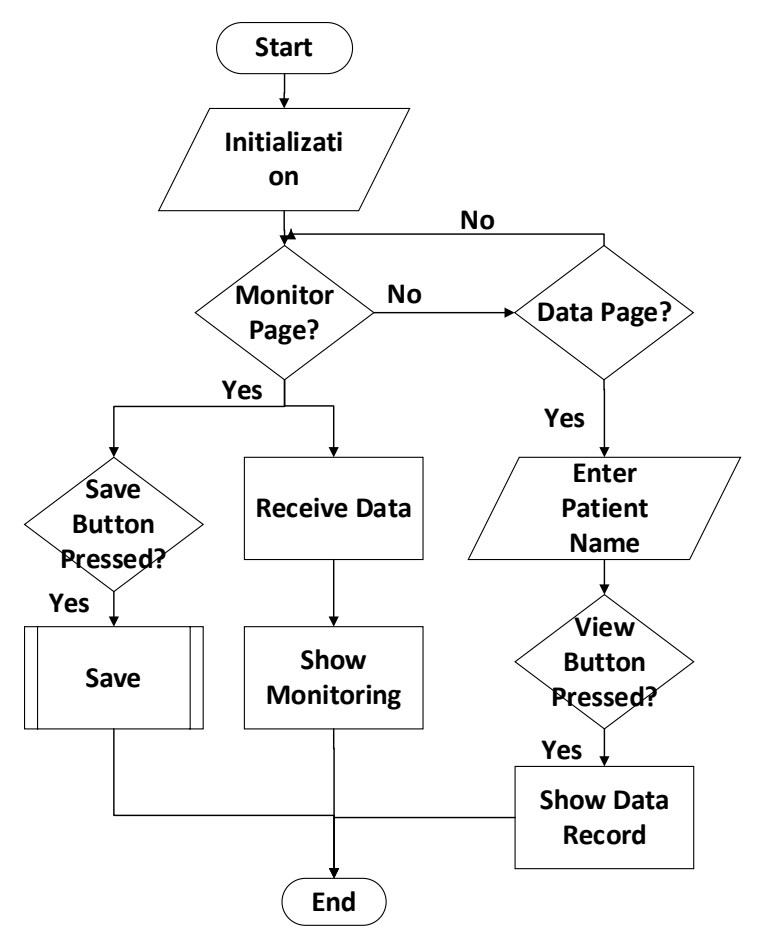

Figure 8. Application flowchart design.

The smartphone application is used to display the results of vital sign measurements in real time, store vital sign data records, and display vital sign data records. Similar to tool design, application design also makes flowcharts in advance to make it easier to make applications that shown in Figure 8.

If you enter the monitoring page, the next process is to receive data from Google Firebase, then display it on the smartphone screen. If on the monitoring page the save button is pressed, it will enter the save subroutine and will save the vital sign value to record vital sign data. If entered on the data page, then write the patient's name. Then if the view button is pressed it will display the results of the patient's vital sign data recording on the smartphone screen.

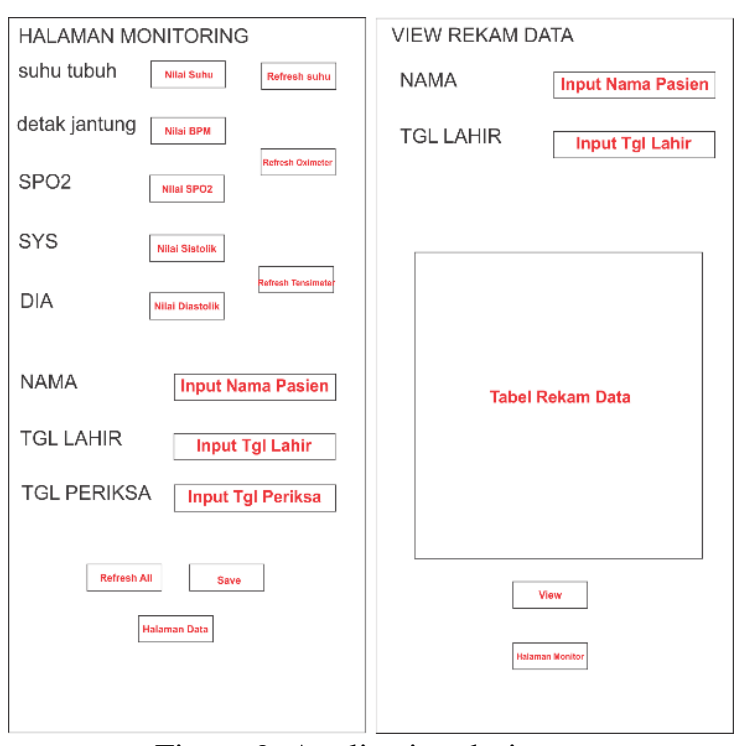

Figure 9. Application design.

The display design of the smartphone application for monitoring the patient's vital signs with an arduino mega-based wireless sensor has two pages, namely the monitoring page and the data record page like shown in Figure 9. The application design of the proposed device used Indonesian language because its designed for Indonesian people. The monitoring page functions to display the vital sign values in real time in the form of digital numbers, while the data record page functions to view the stored vital sign data records. Record vital sign data displayed in a table containing the time of taking vital sign data and the patient's vital sign value.

\section{RESULT AND DISCUSSION}

A patient's vital sign monitoring device with an arduino mega-based wireless sensor serves to measure the patient's vital condition wirelessly or remotely. This tool uses the Atmega 2560 microcontroller found on the Arduino mega development board to process sensors and esp8266 to send data to the firebase server. There are three types of sensors used, namely pulse oximeter sensors, temperature sensors, and blood pressure sensors. The real device design is shown in Figure 10. 


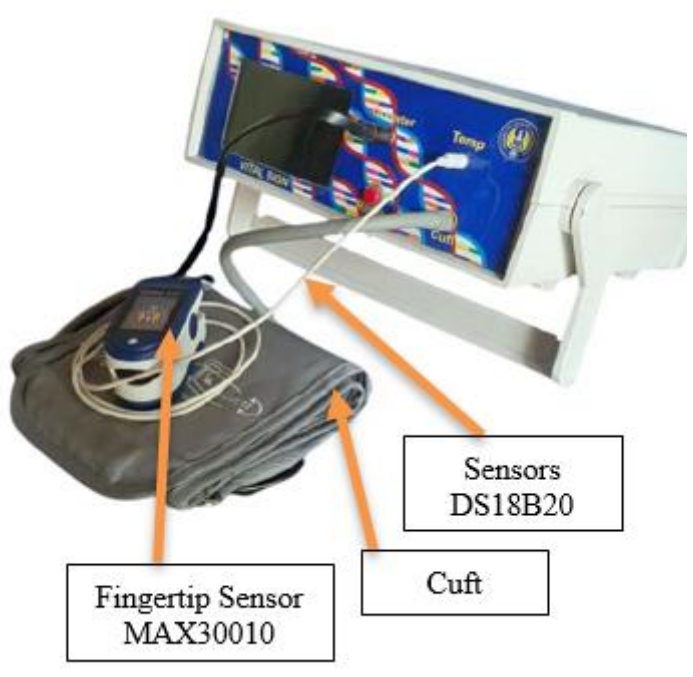

Figure 10. Whole device design.

The quantity measured by the sensor will be processed by the microcontroller and then uploaded to Google Firebase in the form of numerical data from the measured quantity. Measurement or monitoring data on Google Firebase is displayed on the Android application so that monitoring or measurement can be carried out remotely. The data obtained from the measurement process can be stored in the firebase cloud so that it can be used for data analysis of the development of the patient's condition.

The data displayed in the smartphone application is in the form of real-time data from measurement results and recording vital sign data. Real-time data measurement results in the form of body temperature, heart rate, oxygen levels in the blood, and blood pressure of the patient. The display of patient data records is in the form of a table containing the vital sign values along with the date and time when the data is stored. The display of the smartphone application can be seen in Figure 11.

The power supply used in the patient's vital sign monitoring device with an Arduino Mega-based wireless sensor is a switching power supply with an output of 19VDC 3A. This power supply is used because it has a voltage above the voltage needed to charge the battery as the main voltage source when the PLN electricity voltage goes out.

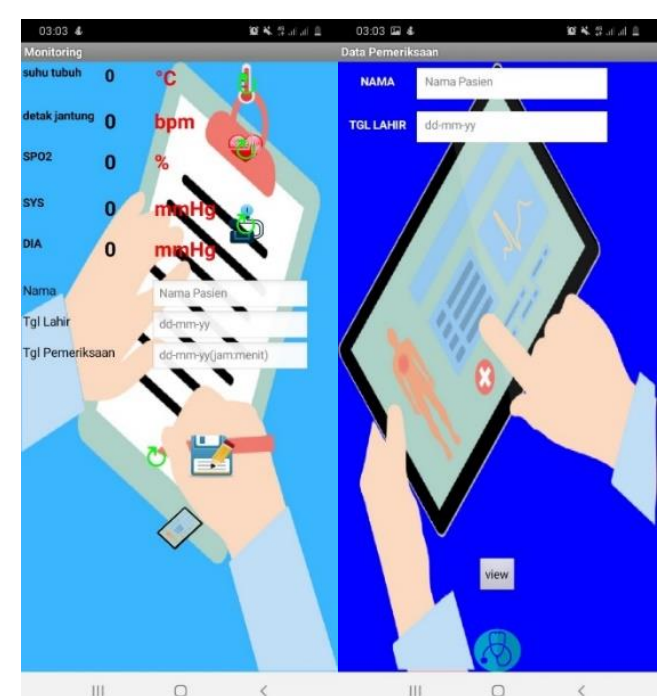

Figure 11. Smartphone application.

The voltage required to charge the battery voltage is $10-15 \%$ higher than the battery voltage. The battery used has a voltage of 12VDC 4.5Ah (2x6VDC). So for charging the battery required a voltage of 13VDC-13.8VDC. Because the power supply used has a voltage of $19 \mathrm{VDC}$, a voltage step-down is needed to lower the $19 \mathrm{~V}$ voltage to the battery charger voltage.

From the battery voltage source and the power supply, a regulator circuit is needed to lower the source voltage to the working voltage of each component in the tool. There are 4 voltages needed in the circuit, namely $12 \mathrm{VDC}$, 5VDC, 3.3VDC, and -5VDC.

3 checks can be done with a patient's vital sign monitoring device with an Arduino Megabased wireless sensor, namely, checking body temperature, checking heart rate and $\mathrm{SPO} 2$, and checking blood pressure. The test was carried out to find out the difference in the measurement of the patient's vital sign monitoring device with an Arduino Mega-based wireless sensor with a comparison tool. The following displays in Figure 12 are the smartphone application results of testing the patient's vital sign monitoring device with an Arduino mega-based wireless sensor.

The test results obtained an average difference of $1.19 \%$ in the measurement of heart rate, $0.77 \%$ in the measurement of oxygen levels 
in the blood, $0.67 \%$ in the measurement of body temperature, $4.78 \%$, and $8.91 \%$ in the measurement of systolic and diastolic blood pressure that shown in Table 1. In measuring blood pressure, the level of difference can be influenced by external factors, namely, the installation of the cuft that is too tight or too loose, the patient's hand is too tense, and the installation of the cuft above the sleeve or does not touch the skin directly.
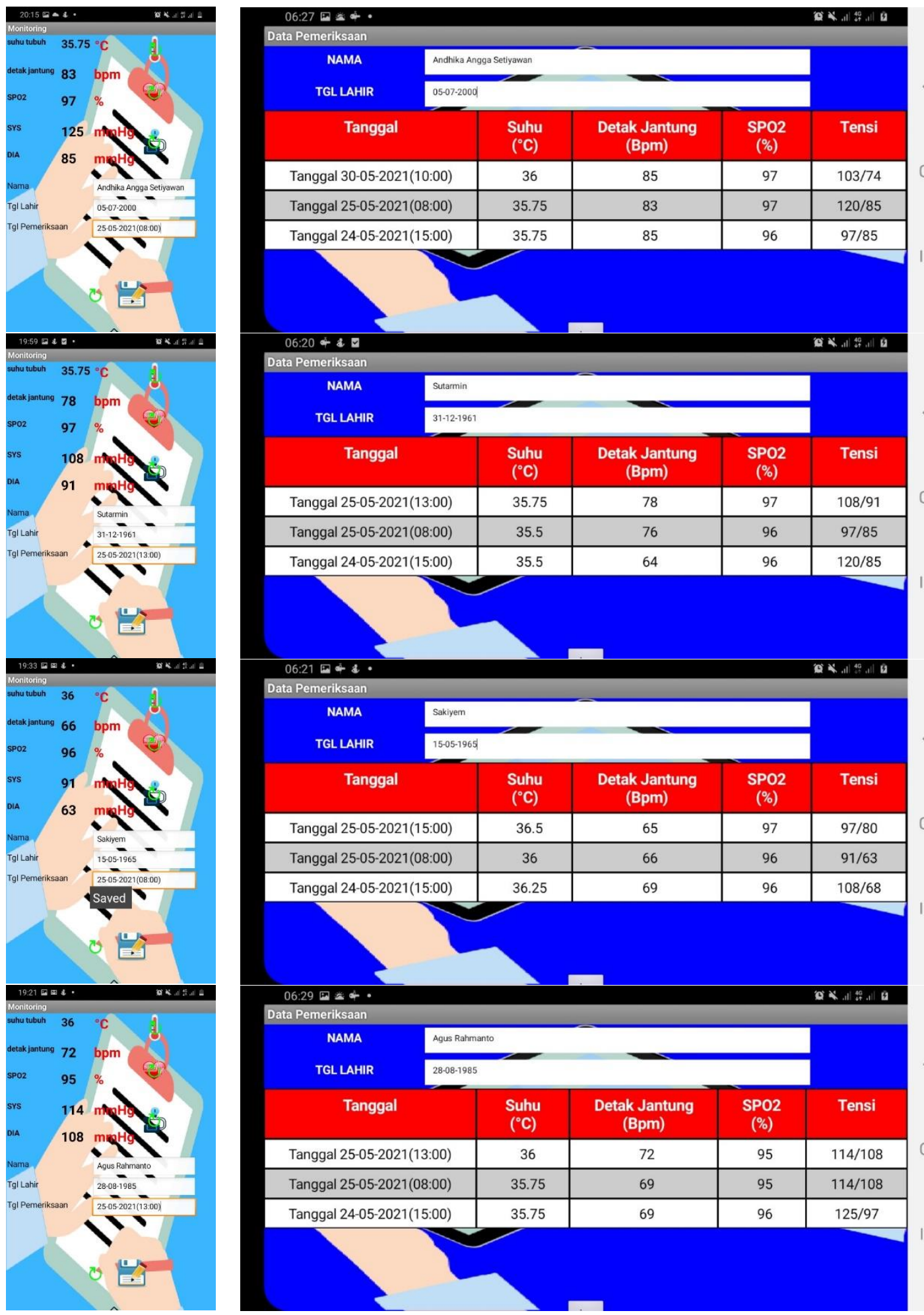

Figure 12. Testing result in smartphone application 
Table 1. Testing result

\begin{tabular}{|c|c|c|c|c|c|c|c|c|c|c|c|c|c|c|c|}
\hline \multirow[t]{2}{*}{ Subject } & \multirow{2}{*}{$\begin{array}{c}\begin{array}{c}\text { Proposed } \\
\text { device }\end{array} \\
\left({ }^{\circ} \mathrm{C}\right)\end{array}$} & \multirow{2}{*}{$\begin{array}{c}\text { Thermometer } \\
\text { Avico AV-08 } \\
\left({ }^{\circ} \mathrm{C}\right)\end{array}$} & \multirow[t]{2}{*}{$\begin{array}{c}\text { Difference } \\
(\%)\end{array}$} & \multicolumn{2}{|c|}{$\begin{array}{c}\text { Proposed } \\
\text { device }\end{array}$} & \multicolumn{2}{|c|}{$\begin{array}{c}\text { Pulse } \\
\text { Oximeter } \\
\text { LK-87 }\end{array}$} & \multicolumn{2}{|c|}{$\begin{array}{c}\text { Difference } \\
(\%)\end{array}$} & \multicolumn{2}{|c|}{$\begin{array}{c}\text { Proposed } \\
\text { device } \\
(\mathrm{mmHg})\end{array}$} & \multicolumn{2}{|c|}{$\begin{array}{l}\text { Tensimeter } \\
\text { Onemed } \\
200(\mathrm{mmhg})\end{array}$} & \multicolumn{2}{|c|}{$\begin{array}{c}\text { Difference } \\
(\%)\end{array}$} \\
\hline & & & & BPM & $\mathrm{SPO}_{2}$ & BPM & $\mathrm{SPO}_{2}$ & BPM & $\mathrm{SPO}_{2}$ & SYS & DYS & SYS & DYS & SYS & DYS \\
\hline \multirow{3}{*}{ Sutarmin } & 35.75 & 36.2 & 1.24 & 78 & 97 & 77 & 97 & 1.30 & 0.00 & 108 & 91 & 110 & 80 & 1.82 & 13.75 \\
\hline & 35.35 & 35.6 & 0.70 & 76 & 96 & 76 & 96 & 0.00 & 0.00 & 97 & 85 & 110 & 80 & 11.82 & 6.25 \\
\hline & 35.5 & 35.6 & 0.28 & 64 & 96 & 65 & 97 & 1.54 & 1.03 & 120 & 85 & 120 & 80 & 0.00 & 6.25 \\
\hline \multirow{3}{*}{ Sakiyem } & 36.5 & 36.2 & 0.83 & 65 & 97 & 65 & 98 & 0.00 & 1.02 & 97 & 80 & 100 & 80 & 3.00 & 0.00 \\
\hline & 36 & 35.5 & 1.41 & 66 & 96 & 66 & 97 & 0.00 & 1.03 & 91 & 63 & 100 & 70 & 9.00 & 10.00 \\
\hline & 36.25 & 36.1 & 0.42 & 69 & 96 & 67 & 97 & 2.99 & 1.03 & 108 & 68 & 100 & 70 & 8.00 & 2.86 \\
\hline \multirow{3}{*}{ Agus R } & 36 & 36.1 & 0.28 & 72 & 95 & 72 & 97 & 0.00 & 2.06 & 114 & 108 & 115 & 90 & 0.87 & 20.00 \\
\hline & 35.75 & 36 & 0.69 & 69 & 95 & 68 & 96 & 1.47 & 1.04 & 114 & 108 & 110 & 90 & 3.64 & 20.00 \\
\hline & 35.75 & 35.7 & 0.14 & 69 & 96 & 66 & 97 & 4.55 & 1.03 & 125 & 97 & 120 & 90 & 4.17 & 7.78 \\
\hline \multirow{3}{*}{$\begin{array}{l}\text { Andhika } \\
\text { A S }\end{array}$} & 36 & 36.1 & 0.28 & 85 & 97 & 83 & 97 & 2.41 & 0.00 & 103 & 74 & 100 & 80 & 3.00 & 7.50 \\
\hline & 35.75 & 36 & 0.69 & 83 & 97 & 83 & 97 & 0.00 & 0.00 & 120 & 85 & 110 & 80 & 9.09 & 6.25 \\
\hline & 35.75 & 35.38 & 1.05 & 85 & 96 & 85 & 97 & 0.00 & 1.03 & 97 & 85 & 100 & 80 & 3.00 & 6.25 \\
\hline \multicolumn{3}{|c|}{ Rata-Rata Perbedaan } & 0.67 & & & & & 1.19 & 0.77 & & & & & 4.78 & 8.91 \\
\hline
\end{tabular}

A patient's vital sign monitoring device with a wireless sensor based on Arduino Mega serves to measure or monitor vital conditions, store vital sign data records, and review vital sign data records. Tests are carried out to whether the patient's vital sign monitoring device with an Arduino mega-based wireless sensor works according to its function and purpose. The test was carried out 12 times to examine 4 different subjects. This test is based on how the tool works.

The workings of the patient's vital sign monitoring device with an Arduino mega-based wireless sensor, namely the sensor will read the patient's vital sign value when the device is given an order or instruction by the user. Instructions or commands are given through the image of the button on the LCD touchscreen. After reading the vital sign, the reading data will be processed by the microcontroller and uploaded to the server in the form of a value in the form of a decimal number. After the data is entered into the data server, it will be displayed in real-time on the smartphone application in the form of decimal numbers. Vital sign data can also be stored on the server to record vital sign data. Record vital sign data seen on the patient data page on the smartphone application in the form of a table.

The test results state that the patient's vital sign monitoring device with an Arduino megabased wireless sensor works well and under its purpose and function, namely being able to measure vital signs remotely, store vital sign data, and display real-time measurement data and record vital sign data.

\section{CONCLUSION}

The device with wireless sensors based on Arduino Mega consists of Arduino Mega with microcontroller ATmega 2560, wifi module esp 8266 to connect to the internet network, temperature sensor DS18B20, sensor pulse oximeter MAX30100, pressure sensor MPX5700AP, signal conditioning circuit, and circuit regulator has tested and implemented. Based on the result, the patient's vital signs can be easier to monitoring.

A patient's vital sign monitoring device with an Arduino Mega-based wireless sensor can 
measure or monitor vital signs, upload vital sign values to the server, store vital sign measurement results to record data, display measurement results in real-time, and record vital sign data on a smartphone application. The average percentage difference between the instrument and the comparator was $0.67 \%$ for measuring temperature, $1.19 \%$ for measuring heart rate, $0.77 \%$ for measuring $\mathrm{SPO} 2$, and $4.78 \%$ and $8.91 \%$ for measuring systolic and diastolic blood pressure.

\section{REFERENCES}

[1] H. Abuella and S. Ekin, "Non-Contact Vital Signs Monitoring through Visible Light Sensing," IEEE Sens. J., vol. 20, no. 7, pp. 3859-3870, 2020, doi: 10.1109/JSEN.2019.2960194.

[2] Z. Alaseel and D. Debnath, "Vital Signs Monitoring System in Cloud Environment," in IEEE International Conference on Electro Information Technology, 2018, pp. 73-78, doi: 10.1109/EIT.2018.8500304.

[3] S. P. McGrath, I. M. Perreard, M. D. Garland, K. A. Converse, and T. A. Mackenzie, "Improving Patient Safety and Clinician Workflow in the General Care Setting With Enhanced Surveillance Monitoring," IEEE J. Biomed. Heal. Informatics, vol. 23 , no. 2, pp. 857-866, 2019, doi: 10.1109/JBHI.2018.2834863.

[4] X. Wang, C. Yang, and S. Mao, "PhaseBeat: Exploiting CSI Phase Data for Vital Sign Monitoring with Commodity WiFi Devices," in International Conference on Distributed Computing Systems, 2017, pp. 1230-1239, doi: 10.1109/ICDCS.2017.206.

[5] N. Q. Al-Naggar, H. M. Al-Hammadi, A. M. Al-Fusail, and Z. A. Al-Shaebi, "Design of a Remote Real-Time Monitoring System for Multiple Physiological Parameters Based on Smartphone," J. Healthc. Eng., vol. 2019, 2019, doi: $10.1155 / 2019 / 5674673$.

[6] C. Zhan, C. K. Tse, Y. Gao, and T. Hao, "Comparative Study of COVID-19 Pandemic Progressions in 175 Regions in Australia, Canada, Italy, Japan, Spain, U.K. And USA Using a Novel Model That Considers Testing Capacity and Deficiency in Confirming Infected Cases," IEEE J. Biomed. Heal. Informatics, vol. 25, no. 8, pp. 2836-2847, 2021, doi:
10.1109/JBHI.2021.3089577.

[7] M. Berquedich, A. Berquedich, O. Kamach, M. Masmoudi, A. Chebbak, and L. Deshayes, "Developing a Mobile COVID19 Prototype Management Application Integrated with an Electronic Health Record for Effective Management in Hospitals," IEEE Eng. Manag. Rev., vol. 48, no. 4, pp. 55-64, 2020, doi: 10.1109/EMR.2020.3032943.

[8] W. Tan and J. Liu, "Application of Face Recognition in Tracing COVID-19 Fever Patients and Close Contacts," in IEEE International Conference on Machine Learning and Applications (ICMLA), 2020, pp. 1112-1116, doi: 10.1109/ICMLA51294.2020.00179.

[9] A. Zafia, "Prototype Alat Monitoring Vital Sign Pasien Rawat Inap Menggunakan Wireless Sensor Sebagai Upaya Physical Distancing menghadapi Covid-19," $J$. Informatics, Inf. Syst. Softw. Eng. Appl., vol. 2, no. 2, pp. 61-68, 2020, doi: 10.20895/inista.v2i2.126.

[10] M. Shu, M. Tang, M. Yang, and N. Wei, "The vital signs real-time monitoring system based on Internet of things," in International Conference on Information Science and Control Engineering (ICISCE), 2017, pp. 747-751, doi: 10.1109/ICISCE.2017.160.

[11] D. Naufal, A. W. Setiawan, and T. L. E. Rajab, "Blood Pressure Measuring Device Based on Korotkoff Sound's Tapping Period and Frequency Detection," in International Seminar on Intelligent Technology and Its Application: Humanification of Reliable Intelligent Systems (ISITIA), 2020, pp. 158-163, doi: 10.1109/ISITIA49792.2020.9163700.

[12] L. Goswami and P. Agrawal, "IoT based Diagnosing of Fault Detection in Power Line Transmission through GOOGLE Firebase Database," in International Conference on Trends in Electronics and Informatics (ICOEI), 2020, pp. 415-420.

[13] M. P. Jati, G. Basuki, and H. Hasnira, "Kendali Fuzzy Logic - Interleaved Boost Converter pada Aplikasi Motor DC," Elinvo (Electronics, Informatics, Vocat. Educ., vol. 5, no. November, pp. 1-9, 2021, doi: 10.21831/elinvo.v5i2.40698. 